\title{
Comparison between Procalcitonin, Brain Natriuretic Peptide, and Uric Acid in Children with Cardiomyopathy and Controls
}

\author{
Noor Mohammad Noori, ${ }^{1}$ Maziar Mahjoubifard, ${ }^{1}$ Iraj Shahramian, \\ Alireza Teimouri, ${ }^{1}$ and Alireza Jahangirifard ${ }^{3}$ \\ ${ }^{1}$ Children and Adolescent Health Research Center, Zahedan University of Medical Sciences, Zahedan 9816743111, Iran \\ ${ }^{2}$ Department of Pediatrics, Faculty of Medicine, Zabol University of Medical Sciences, Zahedan 9816743111, Iran \\ ${ }^{3}$ Shahid Beheshti University of Medical Sciences, Tehran 1985717443, Iran \\ Correspondence should be addressed to Alireza Teimouri; alirezateimouri260@gmail.com
}

Received 6 June 2015; Revised 2 September 2015; Accepted 6 September 2015

Academic Editor: Kimimasa Tobita

Copyright (C) 2015 Noor Mohammad Noori et al. This is an open access article distributed under the Creative Commons Attribution License, which permits unrestricted use, distribution, and reproduction in any medium, provided the original work is properly cited.

\begin{abstract}
Objective. This study was performed to determine the level of procalcitonin, Brain Natriuretic Peptide (BNP), and uric acid in children with cardiomyopathy in comparison with controls and the association with echocardiographic findings. Methods. The levels of BNP, procalcitonin, and serum uric acid were measured and the amounts of biomarkers compared with echocardiographic findings. Results. In this study mean age of participants was the same $(p=0.321)$. The majority of echocardiographic indices in left and right heart have different means in case and controls $(p<0.05)$. Means of BNP, procalcitonin, and uric acid were 213.814 $\pm 309.601,9.326 \pm 3.881$, and $6.846 \pm 1.814$ for case group and $2.76 \pm 1.013,1.851 \pm 1.466$, and $3.317 \pm 0.924$ for control $(p<0.001)$, respectively. In the patients group there was relationship of Ross classification with BNP $\left(\chi^{2}=15.845, p<0.05\right)$ and with age $\left(\chi^{2}=\right.$ $8.946, p<0.05)$. For uric acid and procalcitonin no significant relationships were observed. Conclusions. procalcitonin, uric acid, and BNP had significant relationship with many echocardiographic findings in participants. For patients, procalcitonin did not show correlation. The severity of illness based on the Ross classification showed significant correlation with BNP level and age in patients.
\end{abstract}

\section{Introduction}

Cardiomyopathies, diseases of the heart muscles, primarily affect the left ventricle in which there is the main pumping chamber of the heart. Dilated cardiomyopathy (DCM) is recognized by left ventricular dilation that is concerned with systolic dysfunction. Diastolic dysfunction and impaired right ventricular function can occur. Left or right ventricular failure or both can be risk factors for affected individuals by DCMP. It may lead to ventricular arrhythmia, atrioventricular block, syncope, and sudden death [1]. The yearly incidence is 0.57 per 100000 overall in children which is higher in males $(0.66)$ than in females $(0.47)$, in black (0.98) population than in white $(0.46)$ per 100000 , and in babies younger than 1 year (4.40) than in children (0.34). In adults, the incidence is seven per 100000 population [2,3] and CMP is one of the main causes of heart failure in childhood [4]. NT-pro-BNP (Brain Natriuretic Peptide) is a prehormone synthesized in myocytes released cause of response to stress and increased in hypovolemia, renal failure status and by age [5]. BNP and NT-pro-BNP are extensively used for congestive heart failure diagnosis. These peptides may be useful for screening of asymptomatic high risk patients such as aged persons and patients with hypertensive, diabetic, and coronary artery disease [5]. BNP is a reliable and valuable test for diagnosis of functional and structural disorders of cardiovascular system but with cut-off point in children higher than that in adults [6]. The normal level of BNP is not able to confirm the existence of residual heart disease after cardiac surgery [7]. In cyanotic patients who have an increase in pulmonary artery pressure one observed an increase in serum uric acid level that is related to disease severity [8]. Hyperuricemia is an oxidative stress and is a good prognostic marker in patients with heart failure and is also a new independent risk factor for heart failure in young adults [9]. It was demonstrated that tubular secretion and uric acid clearance decrease in 
TABLE 1: Echocardiographic parameters of left and right heart.

\begin{tabular}{|c|c|c|c|c|c|}
\hline Parameters & Group & Mean & SD & $t$-value & $p$ value \\
\hline \multirow{2}{*}{ Weight (kg) } & Case & 28.703 & 10.553 & \multirow{2}{*}{-1.7896} & \multirow{2}{*}{0.078} \\
\hline & Control & 35.133 & 18.471 & & \\
\hline \multirow{2}{*}{ Left ventricular end-diastolic volume (mL) } & Case & 66.108 & 22.129 & \multirow{2}{*}{5.687} & \multirow{2}{*}{0.000} \\
\hline & Control & 39.279 & 14.782 & & \\
\hline \multirow{2}{*}{ Fractional shortening (\%) } & Case & 35.405 & 8.067 & \multirow{2}{*}{1.2972} & \multirow{2}{*}{0.199} \\
\hline & Control & 33.333 & 3.736 & & \\
\hline \multirow{2}{*}{ Left peak E velocity $(\mathrm{cm} / \mathrm{s})$} & Case & 85.974 & 17.760 & \multirow{2}{*}{-3.4057} & \multirow{2}{*}{0.001} \\
\hline & Control & 101.559 & 19.648 & & \\
\hline \multirow{2}{*}{ Left peak A velocity (cm/s) } & Case & 55.377 & 15.504 & \multirow{2}{*}{-0.5643} & \multirow{2}{*}{0.574} \\
\hline & Control & 57.545 & 15.814 & & \\
\hline \multirow{2}{*}{ Right isovolumic contraction time $(\mathrm{m} / \mathrm{s})$} & Case & 0.034 & 0.017 & \multirow{2}{*}{1.6933} & \multirow{2}{*}{0.095} \\
\hline & Control & 0.0272 & 0.016 & & \\
\hline
\end{tabular}

patients with decompensated severe heart failure and in patients with kidney dysfunction would result an increase in mortality rate [10]. Procalcitonin is a polypeptide made of 116 amino acids and is the precursor of calcitonin. The origin of procalcitonin in the inflammatory response is not yet completely understood. Procalcitonin is produced in the liver and peripheral mononuclear cells and modulated by cytokines [11]. The present study aimed to determine the level of procalcitonin, BNP, and uric acid in patients with dilated cardiomyopathy and in comparison with controls and assess their relationship with echocardiographic findings in participants.

\section{Methods and Materials}

This study was performed in two training hospitals located in Sistan and Baluchestan Province, Zahedan, Iran, from February 2014 to January 2015 among all patients with dilated cardiomyopathy. Patients' age ranged from 1 to 18 years. The study complies with the current ethical considerations. Informed consent was obtained from each patient's parents of the minors included in the study, and the study protocol conforms to the ethical guidelines of the 1975 Declaration of Helsinki as reflected in a priori approval by the institution's Human Research Committee. Exclusion criteria were hemoglobin less than $10 \mathrm{~g} / \mathrm{dL}$, endocrine, metabolic, and valvular disorders, dysrhythmia, and heart block. After considering exclusion criteria 37 patients were included in the study as case group and compared with 37 healthy children who matched in age and gender with case group. The control group was selected according to the normal status in clinical examination and echocardiography. Taking history, physical examination, CXRay, ECG, and echocardiography by MyLab 60 with transducer 3, 8 (made in Italy) were performed for all the participants. In this study, children weights for those over 2 years old were measured using RASA Mark made in Iran by an error of $100 \mathrm{~g}$, while those for children under 2 years old were measured by MIKA Mark recumbent weighing scale made in Japan by an error rate of $10 \mathrm{~g}$. In addition, under-2-year-old children's height was measured in the recumbent position by using a flat wooden calibration table, while that of the children above 2 years old was measured in the standing position with a scale ruler. Heart failure stratification was performed by modified Ross classification. The participant patients were normal in respect of $\mathrm{Na}, \mathrm{K}, \mathrm{Ca}, \mathrm{BUN}$, and creatinine. Three $\mathrm{mL}$ of blood was drawn from the patients while fasting at $8 \mathrm{am}$. Samples were centrifuged at $5^{\circ} \mathrm{C}$ with around $3000 \mathrm{~g}$ for 10 minutes. The separated serum was kept in $-80^{\circ} \mathrm{C}$ refrigerator. The levels of BNP and procalcitonin were measured by ELISA kits. Serum uric acid level was measured by autoanalyser (NMCI). Echocardiography findings were measured by MyLab 60 made in Italy. Since the sample size is larger than 50, we use the Kolmogorov-Smirnov test for variables in the study. The null hypothesis for the test of normality stated that the actual distribution of the variable is equal to the expected distribution; that is, the variable is normally distributed. Since the probability associated with the test of normality for all variables except weight, left ventricular end-diastolic volume, fractional shortening, left peak E velocity, and right isovolumic contraction time is less than or equal to the level of significance (0.05), we reject the null hypothesis and conclude that these variables are normally distributed. Data analysis was performed by SPSS 20.0 software and, in the case of normality, independent $t$-test and one-way ANOVA were used and otherwise same nonparametric tests were applied. For the relationship between variables Pearson correlation was used. In all tests the value of 0.05 was considered for significant differences or correlations.

\section{Results}

In this study 74 children were recruited in equal case and control of 37 subjects. The participants' age ranged from 1 to 18 years with mean of $10.567 \pm 5.5$ and $12.135 \pm 4.626$ years for control and case, respectively, in which $t$-test results show nonsignificant difference $(p=0.321)$. The means of weight are $35.133 \pm 18.471$ and $28.703 \pm 10.553 \mathrm{~kg}$ in control and case groups, respectively $(p=0.078)$. The means of height are $128.721 \pm 29.231$ and $127.405 \pm 18.712 \mathrm{~cm}$ in control and case groups, respectively $(p=0.574)$. Table 1 shows the results of independent $t$-test to compare means 
TABLE 2: Results of the Mann-Whitney $U$ test to compare the groups' values of left heart parameters.

\begin{tabular}{|c|c|c|c|c|c|c|c|}
\hline Parameters & Group & Mean & SD & Mean rank & $\begin{array}{c}\text { Sum of } \\
\text { ranks }\end{array}$ & Mann-Whitney $U$ & Sig. (2-tailed) \\
\hline \multirow{2}{*}{ Height $(\mathrm{cm})$} & Case & 127.405 & 18.712 & 32.797 & 1213.5 & \multirow{2}{*}{510.5} & \multirow{2}{*}{0.574} \\
\hline & Control & 128.7 & 29.2 & 35.483 & 1064.5 & & \\
\hline \multirow{2}{*}{ Ventricular end-diastolic dimension (mm) } & Case & 46.584 & 7.713 & 42.568 & 1575 & \multirow{2}{*}{238} & \multirow{2}{*}{0} \\
\hline & Control & 39.993 & 4.098 & 23.433 & 703 & & \\
\hline \multirow{2}{*}{ Ventricular end-systolic dimension (mm) } & Case & 30.181 & 7.451 & 38.716 & 1432.5 & \multirow{2}{*}{380.5} & \multirow{2}{*}{0.028} \\
\hline & Control & 26.517 & 3.23 & 28.183 & 845.5 & & \\
\hline \multirow{2}{*}{ Ejection fraction (\%) } & Case & 62.514 & 13.715 & 35.986 & 1331.5 & \multirow{2}{*}{481.5} & \multirow{2}{*}{0.353} \\
\hline & Control & 63.533 & 5.507 & 31.55 & 946.5 & & \\
\hline \multirow{2}{*}{ Myocardial performance index } & Case & 0.549 & 0.181 & 45.892 & 1698 & \multirow{2}{*}{115} & \multirow{2}{*}{0} \\
\hline & Control & 0.325 & 0.051 & 19.333 & 580 & & \\
\hline \multirow{2}{*}{ Isovolumic contraction time $(\mathrm{m} / \mathrm{s})$} & Case & 0.03 & 0.01 & 43.865 & 1623 & \multirow{2}{*}{190} & \multirow{2}{*}{0} \\
\hline & Control & 0.017 & 0.007 & 21.833 & 655 & & \\
\hline \multirow{2}{*}{ Isovolumic relaxation time $(\mathrm{m} / \mathrm{s})$} & Case & 0.107 & 0.026 & 43.23 & 1599.5 & \multirow{2}{*}{213.5} & \multirow{2}{*}{0} \\
\hline & Control & 0.094 & 0.012 & 22.617 & 678.5 & & \\
\hline \multirow{2}{*}{ Acceleration time $(\mathrm{m} / \mathrm{s})$} & Case & 0.054 & 0.011 & 33.703 & 1247 & \multirow{2}{*}{544} & \multirow{2}{*}{0.888} \\
\hline & Control & 0.054 & 0.008 & 34.367 & 1031 & & \\
\hline \multirow{2}{*}{ Deceleration time $(\mathrm{m} / \mathrm{s})$} & Case & 0.123 & 0.014 & 35.581 & 1316.5 & \multirow{2}{*}{496.5} & \multirow{2}{*}{0.456} \\
\hline & Control & 0.121 & 0.015 & 32.05 & 961.5 & & \\
\hline $\mathrm{E} / \mathrm{A}$ velocity ratio & Case & 1.657 & 0.757 & 28.757 & 1064 & 361 & 0.014 \\
\hline & Control & 1.842 & 0.461 & 40.467 & 1214 & 301 & 0.014 \\
\hline Left atrium/aorta ratio & Control & 1.252 & 0.294 & 33.662 & 1245.5 & 542.5 & 0.875 \\
\hline Letl atrum/aura ratio & Case & 1.203 & 0.15 & 34.417 & 1032.5 & 342.5 & $0.07 \mathrm{~J}$ \\
\hline & Control & 0.128 & 0.156 & 44.703 & 1654 & 159 & 0 \\
\hline Preejection period (m/s) & Case & 0.094 & 0.101 & 20.8 & 624 & 109 & 0 \\
\hline Preejection period/ejection time $(\mathrm{m} / \mathrm{s})$ & Control & 0.357 & 0.058 & 44.743 & 1655.5 & 157.5 & 0 \\
\hline 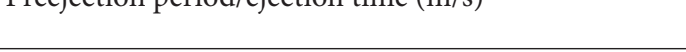 & Case & 0.294 & 0.039 & 20.75 & 622.5 & 107.0 & 0 \\
\hline Ejection time $(\mathrm{m} / \mathrm{s})$ & Control & 0.25 & 0.026 & 27.865 & 1031 & 328 & 0.004 \\
\hline cjection tinte (in/s) & Control & 0.263 & 0.02 & 41.567 & 1247 & $J 20$ & 0.007 \\
\hline ular septal dimension in diastole (mm) & Case & 6.319 & 1.294 & 40.243 & 1489 & 324 & 0.003 \\
\hline interventricular septal amension in diastore ( $\mathrm{mm}$ ) & Control & 5.43 & 0.887 & 26.3 & 789 & 324 & 0.003 \\
\hline Ventricular posterior wall dimension in diastole $(\mathrm{mm})$ & Case & 4.211 & 1.222 & 41.149 & 1522.5 & 290.5 & 0.001 \\
\hline & Control & 3.343 & 0.507 & 25.183 & 755.5 & & \\
\hline ventricular septal dimension in systole ( $\mathrm{mm}$ ) & Case & 9.276 & 1.761 & 39.365 & 1456.5 & 356.5 & 0.012 \\
\hline interventricular septal dimension in systole ( $\mathrm{mm}$ ) & Control & 8.283 & 1.08 & 27.383 & 821.5 & 356.5 & 0.012 \\
\hline & Case & 4.251 & 1.246 & 41.662 & 1541.5 & 271.5 & 0 \\
\hline 1151011 ill sy & Control & 3.363 & 0.524 & 24.55 & 736.5 & $2 / 1.0$ & 0 \\
\hline
\end{tabular}

of echocardiographic findings of left and right heart in case and control groups. Means of left ventricular end-diastolic volume for case and control groups are 66.108 \pm 22.129 and $39.279 \pm 14.782$ with significant different $(t=-5.687, p<$ 0.001 ) and same trends for means of left peak $E$ velocity with $85.974 \pm 17.759$ and $101.558 \pm 19.648$, respectively. The majority of echocardiographic indices in left (Table 2) and right (Table 3 ) heart have different means in case and controls in significant level. Mean rank of the left ventricular end-diastolic dimension of the case group is 42.568 , while the participants in the control group have a left ventricular end-diastolic dimension score rank average of 23.433 with the significance $<0.001$ which shows statistically significant difference. Table 3 showed that the mean ranks of the right E/A velocity ratio were 33.216 and 34.967 in the case and control groups, respectively, with the $p$ value of 0.714 in which there was no enough power to reject equality of mean ranks. Mean of Brain Natriuretic Peptide for case is $213.814 \pm 309.601$ versus control which is $2.76 \pm 1.013$ with the $p$ value less than 0.001 . Procalcitonin and uric acid have same patterns with levels of serum of $9.326 \pm 3.881$ versus $1.85 \pm 11.466$ and $6.84 \pm$ 61.814 versus $3.317 \pm 0.924$ with the $p$ values of 0.001 and 
TABLE 3: Results of the Mann-Whitney $U$ test to compare the groups' values of right heart parameters and biomarkers.

\begin{tabular}{|c|c|c|c|c|c|c|c|}
\hline Parameters & Group & Mean & SD & Mean rank & Sum of ranks & Mann-Whitney $U$ & $p$ \\
\hline \multirow{2}{*}{ Height $(\mathrm{cm})$} & Case & 127.405 & 18.712 & 32.797 & 1213.5 & \multirow{2}{*}{510.5} & \multirow{2}{*}{0.574} \\
\hline & Control & 128.7 & 29.2 & 35.483 & 1064.5 & & \\
\hline \multirow{2}{*}{ Myocardial performance index } & Case & 0.582 & 0.147 & 47.378 & 1753 & \multirow{2}{*}{60} & \multirow{2}{*}{0} \\
\hline & Control & 0.316 & 0.05 & 17.5 & 525 & & \\
\hline \multirow{2}{*}{ Isovolumic relaxation time $(\mathrm{m} / \mathrm{s})$} & Case & 0.11 & 0.022 & 40.176 & 1486.5 & \multirow{2}{*}{326.5} & \multirow{2}{*}{0.004} \\
\hline & Control & 0.096 & 0.012 & 26.383 & 791.5 & & \\
\hline \multirow{2}{*}{ Acceleration time $(\mathrm{m} / \mathrm{s})$} & Case & 0.134 & 0.197 & 30.068 & 1112.5 & \multirow{2}{*}{409.5} & \multirow{2}{*}{0.063} \\
\hline & Control & 0.07 & 0.019 & 38.85 & 1165.5 & & \\
\hline \multirow{2}{*}{ Deceleration time $(\mathrm{m} / \mathrm{s})$} & Case & 0.128 & 0.012 & 38.689 & 1431.5 & \multirow{2}{*}{381.5} & \multirow{2}{*}{0.027} \\
\hline & Control & 0.12 & 0.018 & 28.217 & 846.5 & & \\
\hline \multirow{2}{*}{ Peak E velocity $(\mathrm{cm} / \mathrm{s})$} & Case & 68.413 & 17.158 & 40.203 & 1487.5 & \multirow{2}{*}{325.5} & \multirow{2}{*}{0.004} \\
\hline & Control & 57.706 & 14.139 & 26.35 & 790.5 & & \\
\hline \multirow{2}{*}{ E/A velocity ratio } & Case & 1.408 & 0.478 & 33.216 & 1229 & \multirow{2}{*}{526} & \multirow{2}{*}{0.714} \\
\hline & Control & 1.397 & 0.307 & 34.967 & 1049 & & \\
\hline \multirow{2}{*}{ Peak A velocity $(\mathrm{cm} / \mathrm{s})$} & Case & 50.366 & 13.852 & 40.203 & 1487.5 & \multirow{2}{*}{325.5} & \multirow{2}{*}{0.004} \\
\hline & Control & 42.119 & 9.916 & 26.35 & 790.5 & & \\
\hline \multirow{2}{*}{ Preejection period $(\mathrm{m} / \mathrm{s})$} & Case & 0.085 & 0.015 & 43.054 & 1593 & \multirow{2}{*}{220} & \multirow{2}{*}{0} \\
\hline & Control & 0.076 & 0.008 & 22.833 & 685 & & \\
\hline \multirow{2}{*}{ Preejection period/ejection time } & Case & 0.34 & 0.06 & 45.973 & 1701 & \multirow{2}{*}{112} & \multirow{2}{*}{0} \\
\hline & Control & 0.289 & 0.03 & 19.233 & 577 & & \\
\hline Ejection time $(\mathrm{m} / \mathrm{s})$ & Case & 0.246 & 0.021 & 27.365 & 1012.5 & 309.5 & 0.002 \\
\hline 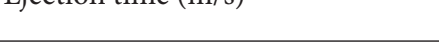 & Control & 0.264 & 0.024 & 42.183 & 1265.5 & & \\
\hline Procalcitonin (ug/L) & Case & 9.326 & 3.881 & 48.351 & 1789 & 24 & 0 \\
\hline 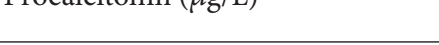 & Control & 1.851 & 1.466 & 16.3 & 489 & & \\
\hline Uric acid (mg/dL) & Case & 6.846 & 1.814 & 48.054 & 1778 & 35 & 0 \\
\hline & Control & 3.317 & 0.924 & 16.667 & 500 & & \\
\hline Brain Natriuretic Peptide (pg/mL) & Case & 213.814 & 309.601 & 48.419 & 1791.5 & 21.5 & 0 \\
\hline & Control & 2.76 & 1.013 & 16.217 & 486.5 & & \\
\hline Age (year) & Case & 12.135 & 4.626 & 36.122 & 1336.5 & 476.5 & 0.321 \\
\hline & Control & 10.567 & 5.5 & 31.383 & 941.5 & & \\
\hline
\end{tabular}

0.001 for case and control, respectively. Table 4 shows Ross classification impact on age and the three biomarkers in the study. The results reveal that, amongst the biomarkers, BNP shows a difference in DCM severity levels. It shows that when DCM level increases the mean rank is increasing. Table 5 shows significant correlation between age, uric acid, and BNP and some of echocardiographic parameters in patients' population. Patients' age has significant correlation with the most echocardiographic parameters except BNP $(r=-0.05$, $p=4.05)$, peak A velocity $(r=-0.302, p=0.069)$, ejection time $(r=0.291, p=0.081)$, and interventricular septal dimension in diastole $(r=-0.172, p=0.309)$. Level of uric acid of patients has significant correlation with BNP $(r=0.707, p<0.001)$ peak A $(r=-0.364, p=0.027)$ and IVSDD $(r=0.548, p=0.000)$. BNP values have significant correlation with Et-p $(r=0.339, p=0.050)$ and IVSDD $(r=0.493, p=0.003)$. Table 6 shows the correlation of echocardiographic parameters and biomarkers in participant's population. Participant age has significant correlation with LVDD $(r=2.28, p=0.02)$, At-L $(r=0.37$, $p=0.000)$, and Et-R $(r=-0.25, p=0.04)$. Weight of participants has significant mostly negative correlation with
At-L $(r=0.31, p=0.01)$, Et-R $(r=-0.25, p=0.04)$, Pep/et-R $(r=-0.25, p=0.04)$, LVPWD $(r=-0.25$, $p=0.04)$, and IVSS $(r=-0.27, p=0.03)$. Height like weight has negative or positive significant correlation with some of echocardiographic parameters or biomarkers, namely, EF $(r=0.24, p=0.05)$, At-L $(r=0.27, p=0.01)$, and dt-R $(r=-0.25, p=0.04)$. Procalcitonin has strong and significant correlation with the most echocardiographic parameters except At-R, dt-R, At-L, EF, and ivds. At the end of study, from 10 patients in group one, 2 patients died due to disease progression. All nine participants in the second group survived until the end of follow-up. In group 3 one patient died and one had heart transplantation (from 10 patients). And finally, for the fourth group, from eight patients, two received heart transplantation, one was with three-chamber pacemaker (died), and two individuals withdrew from the study.

\section{Discussion}

This study demonstrated that LVEDV (left ventricular enddiastolic volume), LVEDD (left ventricular end-diastolic 
TABLE 4: Ross classification impact on age and biomarkers in patients.

\begin{tabular}{|c|c|c|c|c|c|c|c|}
\hline Parameters & $\mathrm{DCM}$ & Mean & SD & $N$ & Mean rank & Chi-Square & $p$ \\
\hline \multirow{4}{*}{ Procalcitonin $(\mu \mathrm{g} / \mathrm{L})$} & 1 & 8.960 & 4.3254 & 10 & 15.2000 & \multirow{4}{*}{5.8195} & \multirow{4}{*}{0.1207} \\
\hline & 2 & 8.022 & 3.9105 & 9 & 16.3333 & & \\
\hline & 3 & 8.925 & 2.4073 & 10 & 19.0500 & & \\
\hline & 4 & 11.750 & 4.3759 & 8 & 26.6875 & & \\
\hline \multirow{4}{*}{ Uric acid (mg/dL) } & 1 & 6.930 & 1.9816 & 10 & 18.6000 & \multirow{4}{*}{0.1515} & \multirow{4}{*}{0.9850} \\
\hline & 2 & 6.944 & 1.8602 & 9 & 20.1667 & & \\
\hline & 3 & 6.840 & 1.5932 & 10 & 18.9000 & & \\
\hline & 4 & 6.637 & 2.1427 & 8 & 18.3125 & & \\
\hline \multirow{4}{*}{ Brain Natriuretic Peptide (pg/mL) } & 1 & 97.130 & 155.2863 & 10 & 12.7500 & \multirow{4}{*}{15.8453} & \multirow{4}{*}{0.0012} \\
\hline & 2 & 76.656 & 76.4345 & 9 & 14.2778 & & \\
\hline & 3 & 133.050 & 102.7770 & 10 & 19.4500 & & \\
\hline & 4 & 614.925 & 452.6220 & 8 & 31.5625 & & \\
\hline \multirow{4}{*}{ Age (year) } & 1 & 8.700 & 4.5473 & 10 & 11.0000 & \multirow{4}{*}{8.9456} & \multirow{4}{*}{0.0300} \\
\hline & 2 & 12.556 & 4.5031 & 9 & 19.7222 & & \\
\hline & 3 & 14.400 & 4.1952 & 10 & 25.1000 & & \\
\hline & 4 & 13.125 & 3.4821 & 8 & 20.5625 & & \\
\hline
\end{tabular}

TABLE 5: Significant matrix correlation of echocardiographic parameters and biomarkers in patients' population.

\begin{tabular}{|c|c|c|c|c|}
\hline \multirow{2}{*}{ Parameters } & \multicolumn{2}{|c|}{ Age } & \multicolumn{2}{|c|}{ Uric acid } \\
\hline & PC & $p$ & PC & $p$ \\
\hline Brain Natriuretic Peptide & -0.05 & 0.776 & 0.703 & 0.000 \\
\hline Left ventricular diastolic dimension & 0.44 & 0.007 & 0.166 & 0.327 \\
\hline Ejection fraction & 0.362 & 0.028 & -0.03 & 0.86 \\
\hline Left isovolumic contraction time & 0.327 & 0.049 & -0.061 & 0.721 \\
\hline Left acceleration time & 0.351 & 0.033 & -0.053 & 0.758 \\
\hline Left peak A velocity & -0.302 & 0.069 & -0.364 & 0.027 \\
\hline Right deceleration time & 0.337 & 0.041 & 0.017 & 0.919 \\
\hline Ejection time & -0.482 & 0.003 & -0.138 & 0.414 \\
\hline Left ejection time & 0.291 & 0.081 & 0.072 & 0.674 \\
\hline Right ejection time & 0.337 & 0.041 & 0.095 & 0.576 \\
\hline Interventricular septal dimension in diastole & -0.172 & 0.309 & 0.548 & 0.000 \\
\hline Ventricular posterior wall dimension in diastole & -0.334 & 0.043 & 0.222 & 0.186 \\
\hline
\end{tabular}

dimension), LVESD (left ventricular end-systolic dimension), MPI (myocardial performance index), ICT (isovolumic contraction time), IRT (isovolumic relaxation time), E (peak E velocity), PEP/ET (preejection period/ejection time), ET (ejection time), IVSDD (interventricular septal dimension in diastole), LVPWDD (left ventricular posterior wall dimension in diastole), IVSDS (interventricular septal dimension in systole), and LVPWDS (left ventricular posterior wall dimension in systole) in left heart and MPI, IRT, DT (deceleration time), E, A (peak A velocity), PEP/ET, PEP, and ET in right heart were significantly different between two groups. We found that in patients with DCM the majority of echocardiographic parameters are increased in case group compared to control group. It also resulted that BNP and procalcitonin were increased significantly according to Ross classification but uric acid decreased nonsignificantly in the case group. Also some echocardiographic parameters were correlated with BNP and uric acid and also it was seen that BNP is a better marker compared with others due to association with severity and progression or regression of disease.

Increased BNP may approve the presence of DCM due to diastolic dysfunction and probably systolic dysfunction but without differentiation power between systolic and diastolic types. Accordingly, BNP has been approved by FDA for diagnosis of heart failure. Similarly we found association between BNP and MPI that shows systolic and diastolic dysfunction [12]. Jefferies and Towbin reported that DCM is characterized with left ventricular dilatation and is accompanied with systolic dysfunction. However diastolic dysfunction may also be seen and both ventricles may develop insufficiency and also there is mortality risk due to ventricular arrhythmia, atrioventricular block, syncope, and sudden death [1]. In our study for the case of patients, we found that BNP had strong relationship with three of echocardiographic findings and severity of illness in which consists with Jefferies' results. Law et al. reported NT-pro-BNP as a good biomarker for continuous left ventricle dysfunction in children with 
TABLE 6: Matrix correlation of echocardiographic parameters and biomarkers in all population.

\begin{tabular}{|c|c|c|c|c|c|c|c|c|}
\hline \multirow{2}{*}{ Echo parameters } & \multicolumn{2}{|c|}{ Age } & \multicolumn{2}{|c|}{ Procalcitonin } & \multicolumn{2}{|c|}{ BNP } & \multicolumn{2}{|c|}{ Uric acid } \\
\hline & $\mathrm{PC}$ & $p$ & $\mathrm{PC}$ & $p$ & $\mathrm{PC}$ & $p$ & $\mathrm{PC}$ & $p$ \\
\hline Left ventricular end-diastolic dimension & 0.28 & 0.02 & 0.29 & 0.02 & 0.33 & 0.01 & 0.48 & 0.00 \\
\hline Left ventricular end-systolic dimension & 0.17 & 0.16 & 0.18 & 0.15 & 0.21 & 0.09 & 0.34 & 0.00 \\
\hline Ejection fraction & 0.22 & 0.07 & 0.00 & 0.98 & -0.03 & 0.83 & -0.08 & 0.54 \\
\hline Left myocardial performance index & 0.14 & 0.27 & 0.39 & 0.00 & 0.15 & 0.25 & 0.49 & 0.00 \\
\hline Left isovolumic contraction time & 0.15 & 0.22 & 0.44 & 0.00 & 0.47 & 0.00 & 0.43 & 0.00 \\
\hline Left isovolumic relaxation time & -0.18 & 0.16 & 0.27 & 0.02 & 0.10 & 0.44 & 0.21 & 0.09 \\
\hline Left acceleration time & 0.37 & 0.00 & -0.11 & 0.38 & -0.12 & 0.33 & 0.01 & 0.92 \\
\hline Left peak E velocity & -0.17 & 0.18 & -0.28 & 0.02 & -0.21 & 0.09 & -0.42 & 0.00 \\
\hline Right myocardial performance index & 0.14 & 0.24 & 0.59 & 0.00 & 0.35 & 0.01 & 0.48 & 0.00 \\
\hline Right isovolumic relaxation time & -0.13 & 0.30 & 0.27 & 0.03 & 0.38 & 0.00 & 0.19 & 0.13 \\
\hline Right deceleration time & -0.07 & 0.56 & 0.11 & 0.36 & 0.20 & 0.12 & 0.26 & 0.03 \\
\hline Right ejection time & -0.25 & 0.04 & 0.27 & 0.03 & 0.03 & 0.79 & 0.19 & 0.12 \\
\hline Right acceleration time & -0.13 & 0.30 & 0.18 & 0.15 & 0.29 & 0.02 & 0.29 & 0.02 \\
\hline Left preejection period/ejection time & 0.08 & 0.51 & 0.30 & 0.01 & 0.19 & 0.13 & 0.31 & 0.01 \\
\hline Right preejection period & -0.10 & 0.44 & 0.26 & 0.03 & 0.40 & 0.00 & 0.34 & 0.00 \\
\hline Right preejection period/ejection time & -0.10 & 0.42 & 0.32 & 0.01 & 0.36 & 0.00 & 0.39 & 0.00 \\
\hline Left interventricular septal dimension in diastole & -0.05 & 0.66 & 0.37 & 0.00 & 0.53 & 0.00 & 0.56 & 0.00 \\
\hline Left ventricular posterior wall dimension in diastole & -0.18 & 0.14 & 0.29 & 0.02 & 0.26 & 0.04 & 0.45 & 0.00 \\
\hline Left interventricular septal dimension in systole & -0.20 & 0.11 & 0.33 & 0.01 & 0.30 & 0.02 & 0.37 & 0.00 \\
\hline Left ventricular posterior wall dimension in systole & -0.15 & 0.21 & 0.35 & 0.00 & 0.32 & 0.01 & 0.47 & 0.00 \\
\hline
\end{tabular}

cardiomyopathy or myocarditis. However the normal level in improved children may not demonstrate any residual heart disease [6]. Their results are similar to our findings but we used BNP instead of NT-pro-BNP. Koch demonstrated that, among children with congenital heart disease, the plasma level of BNP is associated with ventricular function and reflects the ventricular overload injury. So the normal BNP may show compensatory phase [13]. Our results are similar to Koch's when we applied our study on children with DCM. In both studies the major problem is due to volume overload. Mariano-Goulart et al. reported that increased BNP level in patients with systolic ventricular dysfunction should be considered a risk factor for right ventricular dysfunction [14]. In our study it was also revealed that the BNP level was higher in the more severity of disease based on Ross classification. Kremastinos et al. reported that plasma levels of BNP and NT-pro-BNP are increased in major thalassemia patients and when left ventricular dysfunction is developed the predictive value of NT-pro-BNP is better than BNP for diagnosis of latent left ventricular diastolic dysfunction that is also increased by age $[15,16]$. In our study a significant difference in mean age and BNP level was observed in various instances of severity of disease such that, in higher severity, the mean age and the mean BNP were higher. Noori and Rajaei reported that serum uric acid level in patients with DMC is increased and related to some echocardiographic findings. Another study by Cicoira et al. revealed that increased serum uric acid level is associated with diastolic dysfunction [17, 18]. In another study Noori et al. showed that in patients with beta thalassemia systolic and diastolic function of left and right heart were damaged. Also, it is recommended that in patients with major beta thalassemia without clear symptoms and signs of heart involvement the measurements of plasma level of BNP are necessary in addition to serial echocardiography in order to diagnose the early involvement of heart [19]. Krishnan demonstrated that hyperuricemia is an oxidative stress and is a good prognostic factor in patients with heart failure and also a new independent risk factor for heart failure in young patients [9] that agrees with our findings that showed increased serum uric acid level in case group. Niedner et al. found a relationship between BNP and severity of congenital heart disease. But in our study we found that increasing of BNP is correlated with severity of dilated cardiomyopathy [20]. Karoly Gombocz reported that procalcitonin plasma level had higher increase after operation in patients treated by gelatin compared to patients treated by dextran-70. The reason for this low increase in patients treated by dextran-70 would be considered to be due to systemic inflammatory response. An increase of procalcitonin in our patients compared to controls would be due to inflammatory process [11].

Sponholz et al. in a systematic review reported that, after uncomplicated cardiac surgery, procalcitonin levels increase to the peak level within 24 hours and return to normal levels within one week after operation. The degree of procalcitonin elevation depends on the intraoperative course and the type of the surgical procedure. Higher procalcitonin levels were observed in patients with a complicated postoperative course, with infection or sepsis syndromes compared to patients with an uncomplicated course. Procalcitonin is a useful test in differentiating acute graft rejection of heart and lung transplantation from bacterial and fungal, but not from viral, 
infections [21]. In our study the amount of procalcitonin in patient compared to controls increased which maybe was due to chronic inflammatory process. Madershahian et al. reported that procalcitonin increased with maximum concentrations on the second postoperative day. After the second day the levels decrease and will reach the normal concentration at the seventh day. Comparatively it is similar to our results that procalcitonin level increased but was nonsignificant when the degree of Ross classification is increasing. It revealed that when the severity of disease is enhanced the procalcitonin level rises [22].

\section{Conclusion}

The present research was performed on patients with DCM and showed that procalcitonin, uric acid, and Brain Natriuretic Peptide had significant relationship with the majority of echocardiographic parameters when we considered both case and control groups. Procalcitonin did not show any correlation with echocardiographic parameters in patients. The severity of illness based on the Ross classification showed significant and positive correlation with BNP level and age in patients.

\section{Conflict of Interests}

The authors declare no conflict of interests.

\section{Acknowledgments}

The authors show their gratitude to all parents' warm participation especially control groups. The authors also thank nursing staff from hospitals for data gathering.

\section{References}

[1] J. L. Jefferies and J. A. Towbin, "Dilated cardiomyopathy," The Lancet, vol. 375, no. 9716, pp. 752-762, 2010.

[2] N. M. Noori and S. Rajaei, "Serum uric acid correlation with echocardiographic indices in children with dilated cardiomyopathy," The Journal of Tehran University Heart Center, vol. 4, pp. 230-233, 2009.

[3] N. Noori, I. Shahramian, M. Mahjoobifar, A. Teymoori, and Z. Shahraki, "Comparison of calcitonin gene related peptide level between children with dilated cardiomyopathy and control group," International Cardivascular Research Journal, vol. 9, no. 2, pp. 100-105, 2015.

[4] A. W. Nugent, P. E. F. Daubeney, P. Chondros et al., "The epidemiology of childhood cardiomyopathy in Australia," The New England Journal of Medicine, vol. 348, no. 17, pp. 1639-1646, 2003.

[5] E. Braunwald, "Biomarkers in heart failure," The New England Journal of Medicine, vol. 358, no. 20, pp. 2148-2159, 2008.

[6] Y. M. Law, A. W. Hoyer, M. D. Reller, and M. Silberbach, "Accuracy of plasma B-type natriuretic peptide to diagnose significant cardiovascular cisease in children. The better not pout children," Journal of the American College of Cardiology, vol. 54, no. 15, pp. 1467-1475, 2009.

[7] N. Nasser, Z. Perles, A. J. J. T. Rein, and A. Nir, "NT-proBNP as a marker for persistent cardiac disease in children with history of dilated cardiomyopathy and myocarditis," Pediatric Cardiology, vol. 27, no. 1, pp. 87-90, 2006.

[8] N. M. Noori and S. H. Rajaei, "Correlation between serum uric acid level in children with congenital heart disease and severe pulmonary hypertension," Zahedan Journal of Research in Medical Sciences (Tabib-e-Shargh), vol. 8, no. 3, pp. 195-202, 2006 (Persian).

[9] E. Krishnan, "Hyperuricemia and incident heart failure," Circulation: Heart Failure, vol. 2, no. 6, pp. 556-562, 2009.

[10] M. E. Ochiai, A. C. P. Barretto, M. T. Oliveira Jr., R. T. Munhoz, P. C. Morgado, and J. A. F. Ramires, "Uric acid renal excretion and renal insufficiency in decompensated severe heart failure," European Journal of Heart Failure, vol. 7, no. 4, pp. 468-474, 2005.

[11] C. Sponholz, Y. Sakr, K. Reinhart, and F. Brunkhorst, "Diagnostic value and prognostic implications of serum procalcitonin after cardiac surgery: a systematic review of the literature," Critical Care, vol. 10, article R145, 2006.

[12] V. Bhatia, R. Nayyar, and S. Dhindsa, "Brain natriuretic peptide in diagnosis and treatment of heart failure," Journal of Postgraduate Medicine, vol. 49, no. 2, pp. 182-185, 2003.

[13] A. Koch, S. Zink, and H. Singer, "B-type natriuretic peptide in paediatric patients with congenital heart disease," European Heart Journal, vol. 27, no. 7, pp. 861-866, 2006.

[14] D. Mariano-Goulart, M.-C. Eberlé, V. Boudousq et al., "Major increase in brain natriuretic peptide indicates right ventricular systolic dysfunction in patients with heart failure," European Journal of Heart Failure, vol. 5, no. 4, pp. 481-488, 2003.

[15] D. T. Kremastinos, E. Hamodraka, J. Parissis, D. Tsiapras, K. Dima, and A. Maisel, "Predictive value of B-type natriuretic peptides in detecting latent left ventricular diastolic dysfunction in $\beta$-thalassemia major," American Heart Journal, vol. 159, no. 1, pp. 68-74, 2010.

[16] D. T. Kremastinos, D. P. Tsiapras, A. G. Kostopoulou, E. S. Hamodraka, A. S. Chaidaroglou, and E. D. Kapsali, "NTproBNP levels and diastolic dysfunction in $\beta$-thalassaemia major patients," European Journal of Heart Failure, vol. 9, no. 5, pp. 531-536, 2007.

[17] N. M. Noori and S. Rajaei, "Serum uric acid correlation with echocardiographic indices in children with dilated cardiomyopathy," Journal of Tehran University Heart Center, vol. 4, no. 4, pp. 230-233, 2009.

[18] M. Cicoira, L. Zanolla, A. Rossi et al., "Elevated serum uric acid levels are associated with diastolic dysfunction in patients with dilated cardiomyopathy," American Heart Journal, vol. 143, no. 6, pp. 1107-1111, 2002.

[19] N. M. Noori, M. Mohammadi, H. A. Khazaei, and M. Mahjoubifard, "Evaluation of brain natriuretic peptides in early diagnosis of cardiac involvement comparing to echocardiographic findings in major thalassemia patients," The Iranian Journal of Cardiac Surgery, vol. 34, no. 41, pp. 7-12, 2012.

[20] M. F. Niedner, J. L. Foley, R. H. Riffenburgh, D. P. Bichell, B. M. Peterson, and A. Rodarte, "B-type natriuretic peptide: perioperative patterns in congenital heart disease," Congenital Heart Disease, vol. 5, no. 3, pp. 243-255, 2010.

[21] C. Sponholz, Y. Sakr, K. Reinhart, and F. Brunkhorst, "Diagnostic value and prognostic implications of serum procalcitonin after cardiac surgery: a systematic review of the literature," Critical Care, vol. 10, no. 5, article R145, 2006.

[22] N. Madershahian, T. Wittwer, J. Strauch et al., "Kinetic of procalcitonin in the early postoperative course following heart transplantation," Journal of Cardiac Surgery, vol. 23, no. 5, pp. 468-473, 2008. 


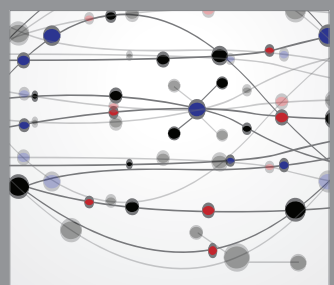

The Scientific World Journal
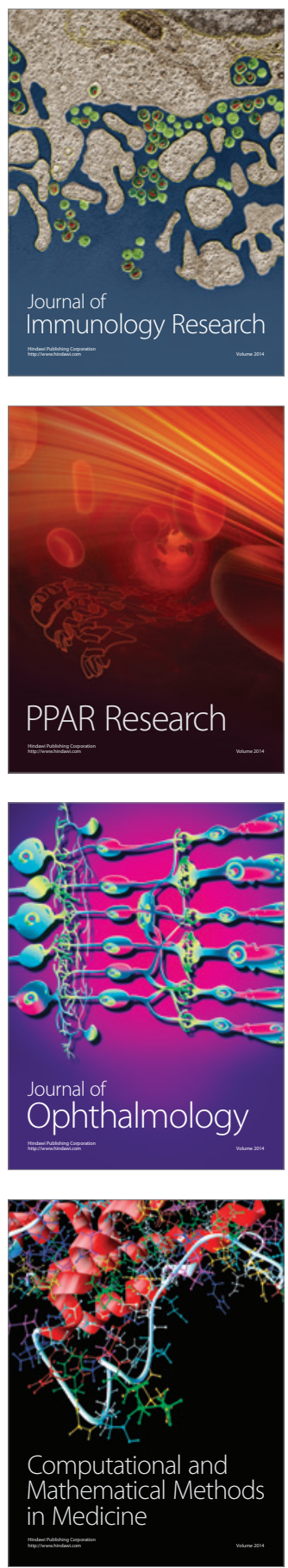

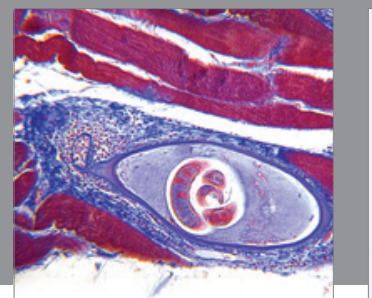

Gastroenterology

Research and Practice
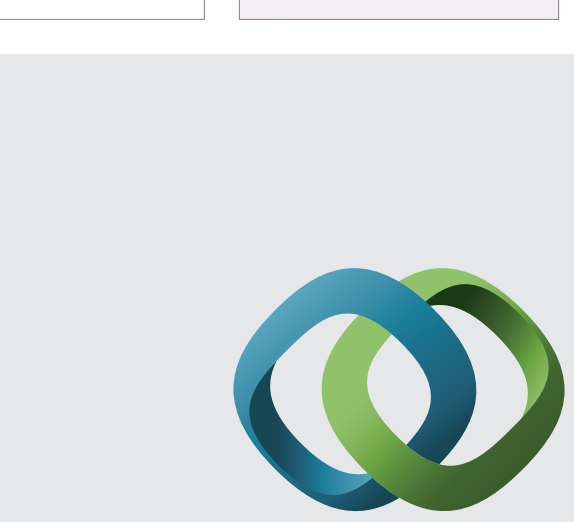

\section{Hindawi}

Submit your manuscripts at

http://www.hindawi.com
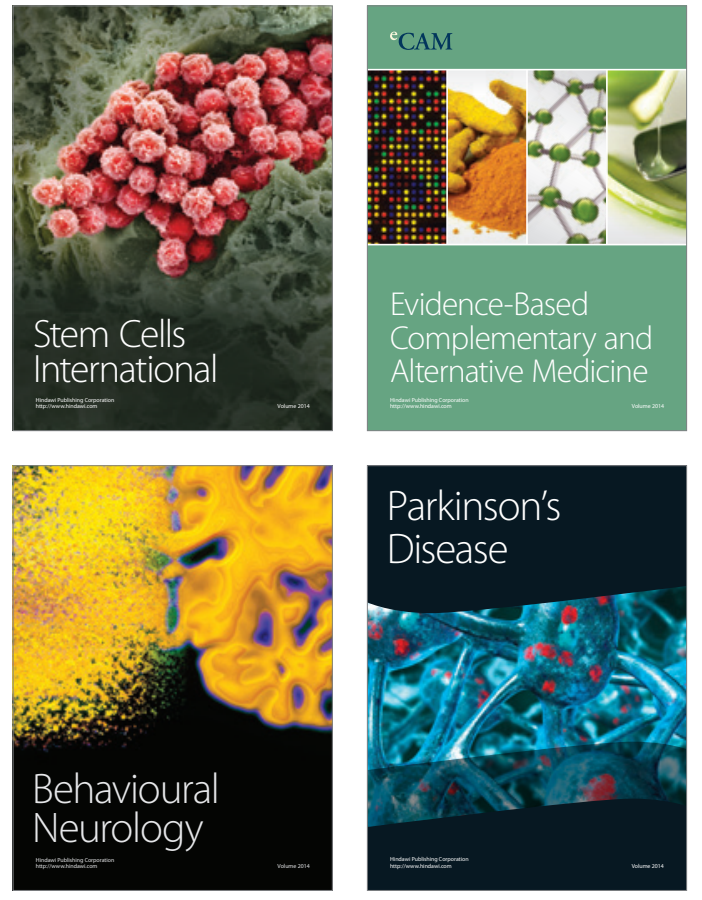
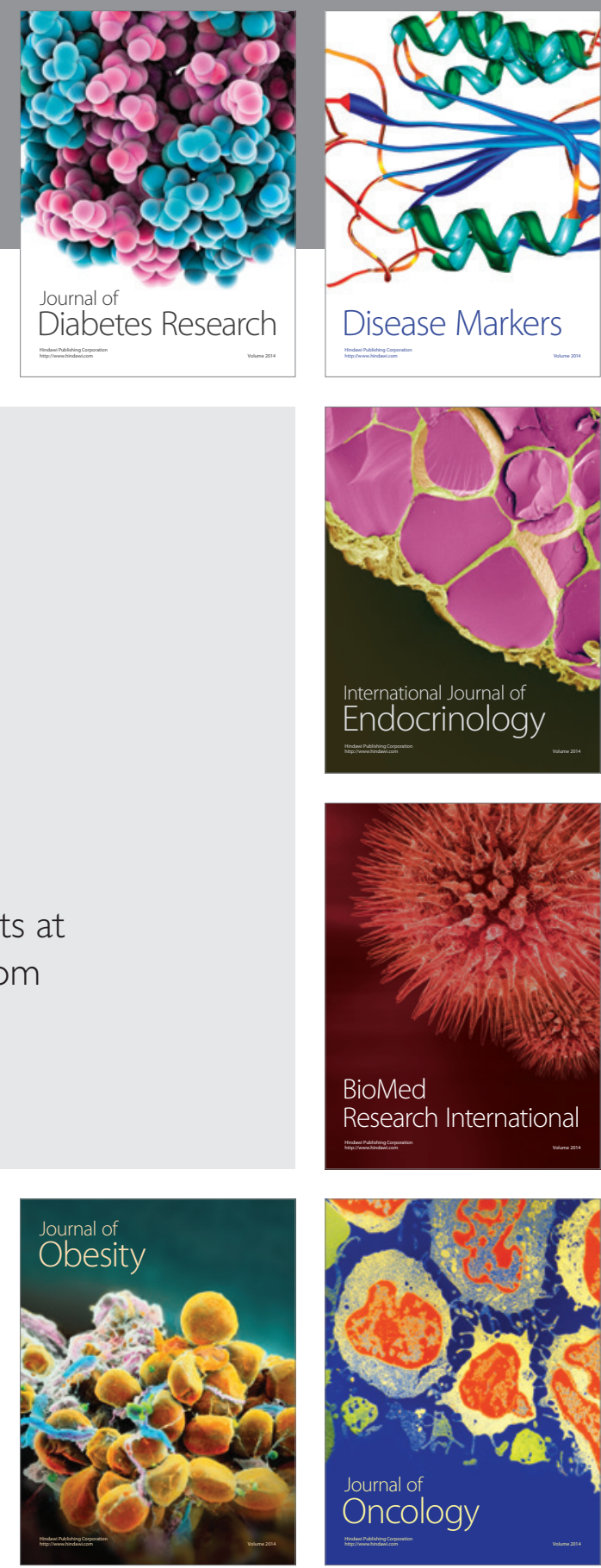

Disease Markers
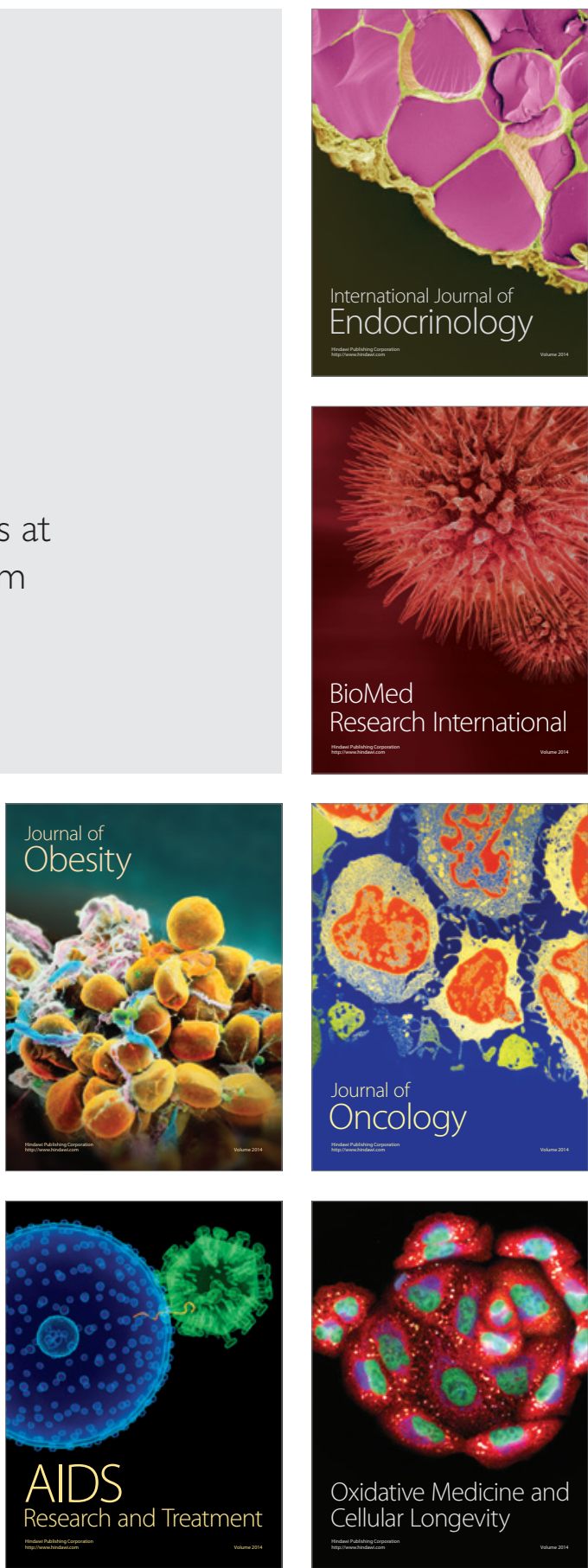